\title{
Pentraxin-3 in non-alcoholic fatty liver disease and its affection by concomitant chronic hepatitis $\mathrm{C}$ infection
}

\author{
Mohamed Makhlouf', Shereen Saleh ${ }^{1 *}$ (D), Marwa Rushdy ${ }^{2}$, Sara Abdelhakam ${ }^{3}$ and Ehab Abd-Elghani ${ }^{1}$
}

\begin{abstract}
Background: Elevated pentraxin-3 (PTX3) is related to liver pathologies such as infections, non-alcoholic fatty liver disease (NAFLD), and tumors. Aim of this study is to evaluate serum PTX3 levels in NAFLD and its affection by concomitant chronic hepatitis $\mathrm{C}$ viral infection (HCV). Seventy subjects were included and divided into 3 groups. Group I included 25 patients with NAFLD. Group II included 25 patients with NAFLD and chronic HCV. Group III included 20 controls. Chronic hepatitis C was diagnosed using quantitative PCR. Plasma pentraxin-3 was measured using ELISA.

Results: Plasma PTX3 was significantly high in group I and group II, when compared to controls. There was nonsignificant difference between groups I and II as regard PTX3 level. Higher PTX3 levels were detected in relation to metabolic syndrome. Cut-off value of PTX3 $\geq 1.8$ was the best to predict metabolic syndrome with $91.4 \%$ sensitivity, 60.0\% specificity, 65.7\% PPV, and 56.7\% NPV.

Conclusion: Serum PTX level in patients with concomitant NAFLD and HCV infection apparently reflects inflammatory response due to changes in metabolic profile, rather than that caused by infection itself, making PTX possibly useful in identifying those at risk of developing metabolic syndrome.
\end{abstract}

Keywords: Pentraxin-3, NAFLD, HCV, Metabolic syndrome

\section{Background}

Non-alcoholic fatty liver disease (NAFLD) represents a group of conditions ranging from asymptomatic simple liver steatosis to non-alcoholic steatohepatitis (NASH), that may progress to cryptogenic cirrhosis and hepatocellular carcinoma $[1,2]$.

Pentraxin-3 (PTX3) is a member of pentraxin superfamily of acute-phase reactants such as C-reactive protein (CRP) and considered as one of the multifunctional soluble recognition receptors that modulate the immunoinflammatory response $[3,4]$. PTX3 is produced from several cells of the innate immune system, primarily the dendritic cells, macrophages, fibroblasts, and activated endothelial cells in response to pro-inflammatory stimuli, such as tumor necrosis factor alpha (TNF- $\alpha$ ), interleukin-1 $\beta$ (IL-1 $\beta$ ), and lipopolysaccharides (LPS), all

\footnotetext{
* Correspondence: shereen_saleh2014@hotmail.com

${ }^{1}$ Internal Medicine Department, Faculty of Medicine, Ain Shams University, Cairo 11566, Egypt

Full list of author information is available at the end of the article
}

of which were considered as essential factors in the pathogenesis of NAFLD and NASH $[5,6]$.

Hepatic steatosis is present in about $50 \%$ of $\mathrm{HCV}$ patients. Genotype 3 was found to be independently associated with hepatic steatosis. Although, other genotypes of $\mathrm{HCV}$, steatosis was associated with features of the metabolic syndrome. HCV replication relies on host lipid metabolism for its lifecycle and results in hepatic steatosis by several mechanisms which enhance lipogenesis, impair mitochondrial lipid oxidation, and downregulate microsomal triglyceride transfer protein (MTTP) activity [7]. Whether HCV replication and hepatic steatosis may lead to liver disease progression and elevation of inflammatory markers is still a wide field for investigation.

The current study aimed to evaluate plasma PTX3 levels in NAFLD patients in comparison to patients with hepatic steatosis and concomitant chronic hepatitis C. 


\section{Methods}

This case control study was performed on 50 adult Egyptian patients collected from Gastroenterology Unit, Internal Medicine, and Tropical Medicine Departments, Ain Shams University. Additionally, 20 apparently healthy subjects were also included as the control group. They were classified into three groups according to the following criteria:

Group I: included 25 patients with NAFLD diagnosed by diffuse hyperechoic echo texture in the abdominal ultrasound and after exclusion of other causes of fatty liver.

Group II: included 25 patients with diffuse hyperechoic echo texture in abdominal ultrasound characteristic of NAFLD and laboratory evidence of chronic hepatitis C viral infection (positive PCR).

Group III: included 20 apparently healthy control subjects with negative medical history, normal physical examination, and normal laboratory and abdominal ultrasound examination.

\section{Exclusion criteria}

Patients consuming significant amount of alcohol more than 21 drinks and 14 drinks per week for men and women respectively; patients receiving drugs which cause fatty liver such as amiodarone, diltiazem, tamoxifen, steroids; patients who take statins as they have lowering effect on plasma PTX3; patients with hepatitis B virus infection; patients with hepatic decompensation, hepatic encephalopathy, ascites, variceal bleeding, elevated serum bilirubin level; patients with chronic kidney diseases; patients with autoimmune diseases; and patients with sepsis, were all excluded from the current study.

Diagnosis of metabolic syndrome in patients having at least 3 of the following 5 criteria:

- Fasting glucose $\geq 100 \mathrm{mg} / \mathrm{dL}$ (or receiving drug therapy for hyperglycemia).

- Blood pressure $\geq 130 / 85 \mathrm{~mm} \mathrm{Hg}$ (or receiving drug therapy for hypertension).

- Triglycerides $\geq 150 \mathrm{mg} / \mathrm{dL}$ (or receiving drug therapy for hypertriglyceridemia).

- High-density lipoprotein-cholesterol (HDL-C) $<40$ $\mathrm{mg} / \mathrm{dL}$ in men or $<50 \mathrm{mg} / \mathrm{dL}$ in women (or receiving drug therapy for reduced HDL-C).

- Waist circumference $\geq 102 \mathrm{~cm}$ in men or $\geq 88 \mathrm{~cm}$ in women [8].

The study protocol was approved by the local ethics committee of Ain-Shams University. This study was performed in accordance with the 1964 Declaration of
Helsinki and all subsequent revisions. All included subjects signed an informed consent prior to the study.

All patients were subjected to the following:

1- Detailed medical history and physical examination.

2- Waist circumference and body mass index (BMI) (body weight in $\mathrm{kg}$ divided by height in square meters $\left(\mathrm{Kg} / \mathrm{m}^{2}\right)$.

3- Abdominal ultrasonography done by Toshiba Aplio XV SSA-770 Ultrasound 2006 (Tustin, California, USA), with examination of liver size, echogenicity, hepatic focal lesion, splenic size, portal vein diameter, and presence of ascites. NAFLD was defined by the presence of diffuse hyperechoic echo texture (bright liver), increased liver echo texture compared with the kidney, vascular blurring, and deep attenuation.

4- Venous blood samples were withdrawn and analyzed for the following:

a- Fasting and 2-h postprandial blood glucose, alanine aminotransferase (ALT), aspartate aminotransferase (AST), serum creatinine, blood urea, serum albumin and serum total bilirubin, total cholesterol, low density lipoprotein (LDL), high density lipoprotein (HDL), and triglycerides (TG); all were measured on Synchron CX9 auto-analyzer (Beckman Instruments Inc.; Scientific Instruments Division, Fullerton, CA 92634-3100, USA) applying enzymatic colorimetric method.

b- Complete blood count (CBC) was done using Coulter counter (T660) (Beckman. Coulter, California, USA).

c- Hepatitis $\mathrm{C}$ virus ( $\mathrm{HCV}$ ) antibody and hepatitis B surface antigen (HBsAg) both were assessed by third generation enzyme linked immunesorbent assay (ELISA).

d- Reverse transcription polymerase chain reaction (RT-PCR) for positive hepatitis $\mathrm{C}$ virus antibody using a commercially available RT-PCR kit and Stratagene Mx3000P device (Corbett Research, Montlake, Australia).

e- Plasma pentraxin-3 was measured using a commercially available enzyme-linked immunosorbent assay (ELISA) kit (Quantikine) (R\&D Systems, Inc. 614 McKinley Place NE Minneapolis, MN 55413, USA).

\section{Statistical methods}

All statistical calculations were done using SPSS (Statistical Package for the Social Science) version 15 for Microsoft Windows (SPSS Inc., 2003). The data were presented as mean $\pm \mathrm{SD}$. The frequencies were calculated for each group, and comparisons were made for categorical 
variables using Chi-square test. Numerical data were compared by using Mann-Whitney U test. Pearson's correlation test was used to evaluate possible correlations between quantitative variables. $p$ value of $<0.05$ was considered statistically significant.

\section{Results}

The demographic and laboratory characteristics of patients and control groups are presented in Table 1. There was a highly significant difference between the three studied groups regarding body weight, body mass index, and waist circumference. On comparing between group I (NAFLD patients) and group II (NAFLD patients with $\mathrm{HCV}$ ), there was a highly significant difference regarding body weight, body mass index, and waist circumference, Table 2.

Plasma levels of PTX3 showed significantly higher values in both (group I) and (group II), when compared to (group III). On the other hand, there was non- significant difference between groups I and II as regard PTX3 with $p$ value $=0.50$, Table 3 .

Thirty-five patients were diagnosed to have metabolic syndrome. On comparing between patients with and without metabolic syndromes, significant higher levels of plasma pentraxin-3 was found in patients with metabolic syndrome (Fig. 1).

There was a significant positive correlation between PTX3 and each of body mass index, waist circumference, fasting blood sugar, serum triglyceride, serum LDL, PCR for $\mathrm{HCV}$, serum ALT, serum AST, total and direct bilirubin, and total cholesterol. While, there was a significant negative correlation between PTX3 and each of HDL, serum albumin, and platelet count (Table 4).

Receiver operating characteristic (ROC) curve was constructed to assess accuracy of PTX3 to detect presence or absence of metabolic syndrome. It shows that a cut-off value for PTX $3 \geq 1.8 \mathrm{ng} / \mathrm{mL}$ was the best to predict metabolic syndrome with $91.4 \%$ sensitivity, $60.0 \%$ specificity, $65.7 \%$ positive predictive value

Table 1 Characteristics of the three study groups

\begin{tabular}{|c|c|c|c|}
\hline \multirow[t]{2}{*}{ Parameter } & $\begin{array}{l}\text { Group I } \\
\text { NAFLD patients }(n=25)\end{array}$ & $\begin{array}{l}\text { Group II } \\
\text { NAFLD patients with HCV }(n=25)\end{array}$ & $\begin{array}{l}\text { Group III } \\
\text { Healthy control }(N=20)\end{array}$ \\
\hline & \multicolumn{3}{|c|}{ Mean \pm SD } \\
\hline Age (in years) & $42.7 \pm 11.2$ & $43.3 \pm 9.6$ & $42.4 \pm 6.9$ \\
\hline Body weight (Kg) & $94.8 \pm 16.8$ & $79.6 \pm 10.1$ & $69.7 \pm 4.7$ \\
\hline Height (cm) & $167.7 \pm 8.9$ & $171.2 \pm 9.8$ & $171.3 \pm 3.2$ \\
\hline Body mass index $\left(\mathrm{Kg} / \mathrm{m}^{2}\right)$ & $33.0 \pm 5.1$ & $26.7 \pm 2.4$ & $23.7 \pm 1.6$ \\
\hline Waist circumference (cm) & $110.8 \pm 15.0$ & $98.8 \pm 9.5$ & $83.9 \pm 8.0$ \\
\hline PCR for HCV (IU/mL) & - & $765,324.9 \pm 1,510,564.0$ & - \\
\hline $\operatorname{ALT}(U / L)$ & $45.1 \pm 20.4$ & $75.4 \pm 27.1$ & $13.9 \pm 2.1$ \\
\hline AST (U/L) & $40.6 \pm 16.9$ & $52.6 \pm 20.4$ & $10.7 \pm 1.8$ \\
\hline Albumin (g/dL) & $4.1 \pm 0.2$ & $4.1 \pm 0.5$ & $5.5 \pm 0.4$ \\
\hline Total bilirubin (mg/dL) & $0.8 \pm 0.2$ & $0.7 \pm 0.2$ & $0.3 \pm 0.1$ \\
\hline Direct bilirubin (mg/dL) & $0.3 \pm 0.1$ & $0.2 \pm 0.1$ & $0.1 \pm 0.04$ \\
\hline Hemoglobin (g/dL) & $13.5 \pm 1.2$ & $13.1 \pm 1.2$ & $14.4 \pm 0.6$ \\
\hline WBC $\left({ }^{*} 10^{3} / \mathrm{cmm}\right)$ & $8.1 \pm 1.2$ & $7.2 \pm 2.2$ & $8.5 \pm 0.8$ \\
\hline $\operatorname{PLT}\left({ }^{*} 10^{3} / \mathrm{cmm}\right)$ & $256.5 \pm 63.2$ & $226.2 \pm 48.6$ & $297.0 \pm 20.5$ \\
\hline Serum creatinine (mg/dL) & $0.8 \pm 0.2$ & $0.8 \pm 0.2$ & $0.8 \pm 0.1$ \\
\hline Urea (mg/dL) & $19.2 \pm 3.1$ & $17.2 \pm 2.1$ & $18.5 \pm 2.0$ \\
\hline Fasting blood sugar (mg/dL) & $98.2 \pm 48.4$ & $78.1 \pm 11.5$ & $70.2 \pm 4.6$ \\
\hline Post prandial blood sugar (mg/dL) & $125.6 \pm 44.8$ & $103.3 \pm 19.4$ & $92.0 \pm 4.2$ \\
\hline Triglyceride (mg/dL) & $203.2 \pm 75.0$ & $161.2 \pm 16.2$ & $108.4 \pm 10.6$ \\
\hline $\mathrm{HDL}(\mathrm{mg} / \mathrm{dL})$ & $35.4 \pm 3.8$ & $33.8 \pm 2.4$ & $41.5 \pm 6.1$ \\
\hline LDL (mg/dL) & $164.7 \pm 24.3$ & $146.4 \pm 11.1$ & $88.6 \pm 7.9$ \\
\hline Total Cholesterol (mg/dL) & $222.2 \pm 30.5$ & $195.6 \pm 12.3$ & $157.3 \pm 5.7$ \\
\hline Plasma PTX3 (ng/mL) & $5.5 \pm 4.9$ & $5.8 \pm 4.5$ & $0.9 \pm 0.5$ \\
\hline
\end{tabular}

ALT alanine aminotransferase, $A S T$ aspartate aminotransferase, $H C V$ hepatitis C virus, HDL high-density lipoprotein, $L D L$ low-density lipoprotein, NAFLD nonalcoholic fatty liver disease, PTX3 pentraxin-3 
Table 2 Comparative analysis between the studied groups as regard age, sex, and anthropometric measurements

\begin{tabular}{|c|c|c|c|c|c|c|}
\hline \multirow{2}{*}{\multicolumn{2}{|c|}{ Parameter }} & \multicolumn{3}{|c|}{ Group (Mean \pm SD) } & \multirow{2}{*}{$\begin{array}{l}p \text { value } \\
\text { between } \\
\text { three } \\
\text { groups }\end{array}$} & \multirow{2}{*}{$\begin{array}{l}p \text { value } \\
\text { between } \\
\text { groups I } \\
\text { and II }\end{array}$} \\
\hline & & $\begin{array}{l}\text { Group I } \\
\text { NAFLD patients } \\
(n=25)\end{array}$ & $\begin{array}{l}\text { Group II } \\
\text { NAFLD patients with HCV } \\
(n=25)\end{array}$ & $\begin{array}{l}\text { Group III } \\
\text { Healthy control } \\
(n=20)\end{array}$ & & \\
\hline \multicolumn{2}{|l|}{ Age (in years) } & $42.7 \pm 11.2$ & $43.3 \pm 9.6$ & $42.4 \pm 6.9$ & 0.92 & 0.83 \\
\hline \multirow[t]{2}{*}{ Sex (freq. (\%)) } & Males & $11(44.0)$ & $11(44.0)$ & $8(40.0)$ & 0.95 & 1.00 \\
\hline & Females & $14(56.0)$ & $14(56.0)$ & $12(60.0)$ & & \\
\hline \multicolumn{2}{|c|}{ Body weight (Kg) } & $94.8 \pm 16.8$ & $79.6 \pm 10.1$ & $69.7 \pm 4.7$ & $<0.001^{\mathrm{a}}$ & $<0.001^{b}$ \\
\hline \multicolumn{2}{|l|}{ Height (cm) } & $167.7 \pm 8.9$ & $171.2 \pm 9.8$ & $171.3 \pm 3.2$ & 0.25 & 0.17 \\
\hline \multicolumn{2}{|c|}{ Body mass index $\left(\mathrm{Kg} / \mathrm{m}^{2}\right)$} & $33.0 \pm 5.1$ & $26.7 \pm 2.4$ & $23.7 \pm 1.6$ & $<0.001^{\mathrm{a}}$ & $<0.001^{b}$ \\
\hline \multicolumn{2}{|c|}{ Waist circumference $(\mathrm{cm})$} & $110.8 \pm 15.0$ & $98.8 \pm 9.5$ & $83.9 \pm 8.0$ & $0.003^{\mathrm{a}}$ & $0.003^{b}$ \\
\hline
\end{tabular}

HCV hepatitis C virus, NAFLD nonalcoholic fatty liver disease

${ }^{a}$ Kruskal-Wallis test is statistically significant at $95 \%$ confidence level

${ }^{b}$ Mann-Whitney test is statistically significant at $95 \%$ confidence level

(PPV), and $56.7 \%$ negative predictive value (NPV) (Fig. 2).

\section{Discussion}

NAFLD is one of the most common forms of chronic liver diseases among obese patients and as one of the features of the metabolic syndrome [9]. It is characterized by accumulation of large triglyceride droplets within the liver cells [10].

Serum PTX3 level increases rapidly in inflammatory conditions, reaching its peak values after $6-8 \mathrm{~h}$ of any inflammatory condition; its elevation on the early phase is due to rapid release of stored PTX3 by the activated neutrophils [11, 12]. The short pentraxins, CRP, and serum amyloid protein are produced by the liver as a systemic response to local inflammation, whereas expression of the long pentraxin (PTX3) is induced by the damaged tissues [13].

In the current study, the aim was to evaluate plasma PTX3 levels in NAFLD patients in comparison to patients with hepatic steatosis and concomitant chronic hepatitis C.

The diagnosis of NAFLD in this study relied on the characteristic abdominal ultrasonographic features such as the presence of diffuse hyperechoic echo texture (bright liver), increased liver echo texture compared with the kidney, vascular blurring, and deep attenuation, together with the exclusion of other causes of fatty liver such as significant alcohol consumption, drug induced hepatitis, and chronic viral hepatitis.

Although liver biopsy is the gold standard diagnostic test of NAFLD, liver biopsy is an invasive procedure that carries a risk of complications together with sampling errors and intra- and interobserver variability. For that reasons, liver biopsy is considered an "imperfect Gold Standard diagnostic tool" [14]. Depending solely on ultrasound in the diagnosis of NAFLD is considered a weak point in the current study as it is less sensitive than liver biopsy or magnetic resonance elastography. On the other hand, ultrasound is widely available, of low cost and non-invasive. Most of the recent studies relied on the ultrasonographic diagnosis of NAFLD after exclusion of other causes of liver diseases [15].

We found that plasma levels of PTX3 were significantly higher in patients with NAFLD in comparison to controls. Our results agreed with the study of Yoneda et al. [3] which revealed that PTX3 levels were significantly higher in NAFLD patients than healthy control subjects. Kadir et al. [16] had demonstrated that PTX3

Table 3 Comparison between the studied groups as regard plasma PTX3 (ng/mL)

\begin{tabular}{|c|c|c|c|c|c|c|c|c|}
\hline \multirow[t]{2}{*}{ Group } & \multirow[t]{2}{*}{$N$} & \multirow[t]{2}{*}{ Mean \pm SD } & \multirow[t]{2}{*}{ Range } & \multicolumn{3}{|c|}{ Percentiles } & \multirow{2}{*}{$\begin{array}{l}p \text { value } \\
\text { between } \\
\text { three groups }\end{array}$} & \multirow{2}{*}{$\begin{array}{l}p \text { value } \\
\text { between } \\
\text { groups I and II }\end{array}$} \\
\hline & & & & 25th & 50th (median) & 75th & & \\
\hline $\begin{array}{l}\text { Group I } \\
\quad \text { NAFLD patients }\end{array}$ & 25 & $5.5 \pm 4.9$ & $0.3-20$ & 2.5 & 4.0 & 6.6 & $<0.001^{a}$ & $0.5^{b}$ \\
\hline $\begin{array}{l}\text { Group II } \\
\quad \text { NAFLD patients with HCV }\end{array}$ & 25 & $5.8 \pm 4.5$ & $0.3-21$ & 3.0 & 4.5 & 8.0 & & \\
\hline $\begin{array}{l}\text { Group III } \\
\quad \text { Healthy control }\end{array}$ & 20 & $0.9 \pm 0.5$ & $0.2-2.1$ & 0.5 & 0.9 & 1.2 & & \\
\hline
\end{tabular}

HCV hepatitis C virus, NAFLD nonalcoholic fatty liver disease

${ }^{a}$ Kruskal-Wallis test is statistically significant at $95 \%$ confidence level

${ }^{\mathrm{b}}$ Mann-Whitney test is statistically significant at $95 \%$ confidence level 


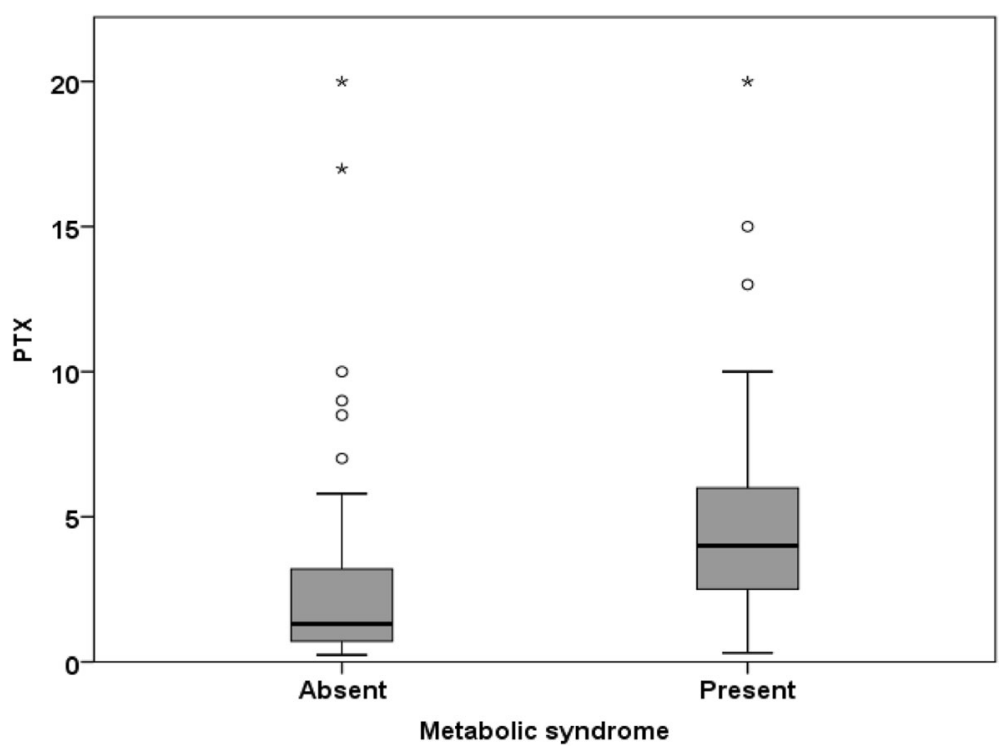

Fig. 1 Box-plot chart showing values of PTX3 (median, range) in the presence or absence of metabolic syndrome

Table 4 Correlation between PTX3 (ng/mL) and all other parameters

\begin{tabular}{|c|c|c|}
\hline Parameter & Correlation coefficient & $p$ value \\
\hline Age (in years) & -0.02 & 0.880 \\
\hline Body weight (Kg) & 0.22 & 0.073 \\
\hline Height (cm) & -0.16 & 0.195 \\
\hline Body mass index $\left(\mathrm{Kg} / \mathrm{m}^{2}\right)$ & $0.30^{\mathrm{a}}$ & 0.013 \\
\hline Smoking index & -0.001 & 0.993 \\
\hline Waist circumference $(\mathrm{cm})$ & $0.35^{\mathrm{a}}$ & $<0.003$ \\
\hline Fasting blood sugar (mg/dL) & $0.29^{\mathrm{a}}$ & 0.015 \\
\hline Post prandial blood sugar (mg/dL) & 0.23 & 0.054 \\
\hline Triglyceride (mg/dL) & $0.55^{\mathrm{a}}$ & $<0.001$ \\
\hline $\mathrm{HDL}(\mathrm{mg} / \mathrm{dL})$ & $-0.24^{\mathrm{a}}$ & 0.048 \\
\hline $\mathrm{LDL}(\mathrm{mg} / \mathrm{dL})$ & $0.47^{\mathrm{a}}$ & $<0.001$ \\
\hline PCR for HCV (IU/mL) & $0.36^{\mathrm{a}}$ & 0.002 \\
\hline $\mathrm{ALT}(\mathrm{U} / \mathrm{L})$ & $0.46^{\mathrm{a}}$ & $<0.001$ \\
\hline AST $(U / L)$ & $0.46^{\mathrm{a}}$ & $<0.001$ \\
\hline Albumin (g/dL) & $-0.63^{\mathrm{a}}$ & $<0.001$ \\
\hline Total bilirubin (mg/dL) & $0.66^{\mathrm{a}}$ & $<0.001$ \\
\hline Direct bilirubin (mg/dL) & $0.61^{\mathrm{a}}$ & $<0.001$ \\
\hline Hemoglobin (g/dL) & -0.23 & 0.054 \\
\hline WBC $\left({ }^{*} 10^{3} / \mathrm{cmm}\right)$ & -0.12 & 0.342 \\
\hline $\operatorname{PLT}\left({ }^{x} 10^{3} / \mathrm{cmm}\right)$ & $-0.41^{a}$ & $<0.001$ \\
\hline Serum creatinine $(\mathrm{mg} / \mathrm{dL})$ & -0.14 & 0.26 \\
\hline Urea (mg/dL) & -0.041 & 0.739 \\
\hline Total Cholesterol (mg/dL) & $0.50^{\mathrm{a}}$ & $<0.001$ \\
\hline
\end{tabular}

ALT alanine aminotransferase, AST aspartate aminotransferase, $H C V$ hepatitis $C$ virus, $H D L$ high-density lipoprotein, $L D L$ low-density lipoprotein

asignificant levels in NAFLD patients with fibrosis were higher than NAFLD patients without fibrosis and healthy subjects, independent of metabolic syndrome components. On the other hand, Maleki et al. [17] found no significant difference between NAFLD and healthy control subjects regarding plasma PTX3.

In the present study, there was non-significant difference between NAFLD patients with and without chronic HCV regarding plasma PTX3. PTX3 is directly produced by damaged tissues, and a rapid increase indicates inflammation. Elevated PTX3 concentrations are related to liver-associated pathological conditions such as liver infections, NAFLD, NASH, and hepatic tumors [18]. In a study performed by Carmo et al. [19], patients with hepatocellular carcinoma (HCC) on top of $\mathrm{HCV}$ were found to have higher PTX3 plasma levels than individuals with mild or severe fibrosis. They concluded that PTX3 seems to be a risk factor for the occurrence of HCC in chronic hepatitis C [19].

Significant positive correlation between plasma PTX3 and HCV quantitative PCR was found in the current study. PTX3, the prototype of the long pentraxin group, is a critical component of the humoral arm of innate immunity and opsonic activity. It facilitates pathogen recognition and produced by a variety of tissues and cells in response to pro-inflammatory signals and Toll-like receptor engagement [20]. The persistent elevation in PTX3 levels is associated with disease severity and increased morbidity in several clinical conditions. Persistently elevated PTX3 may represent a novel and promising biomarker of liver disease [21].

In the present study, significant positive correlations were found between serum PTX3 levels and body mass index (BMI), waist circumference, fasting blood sugar 


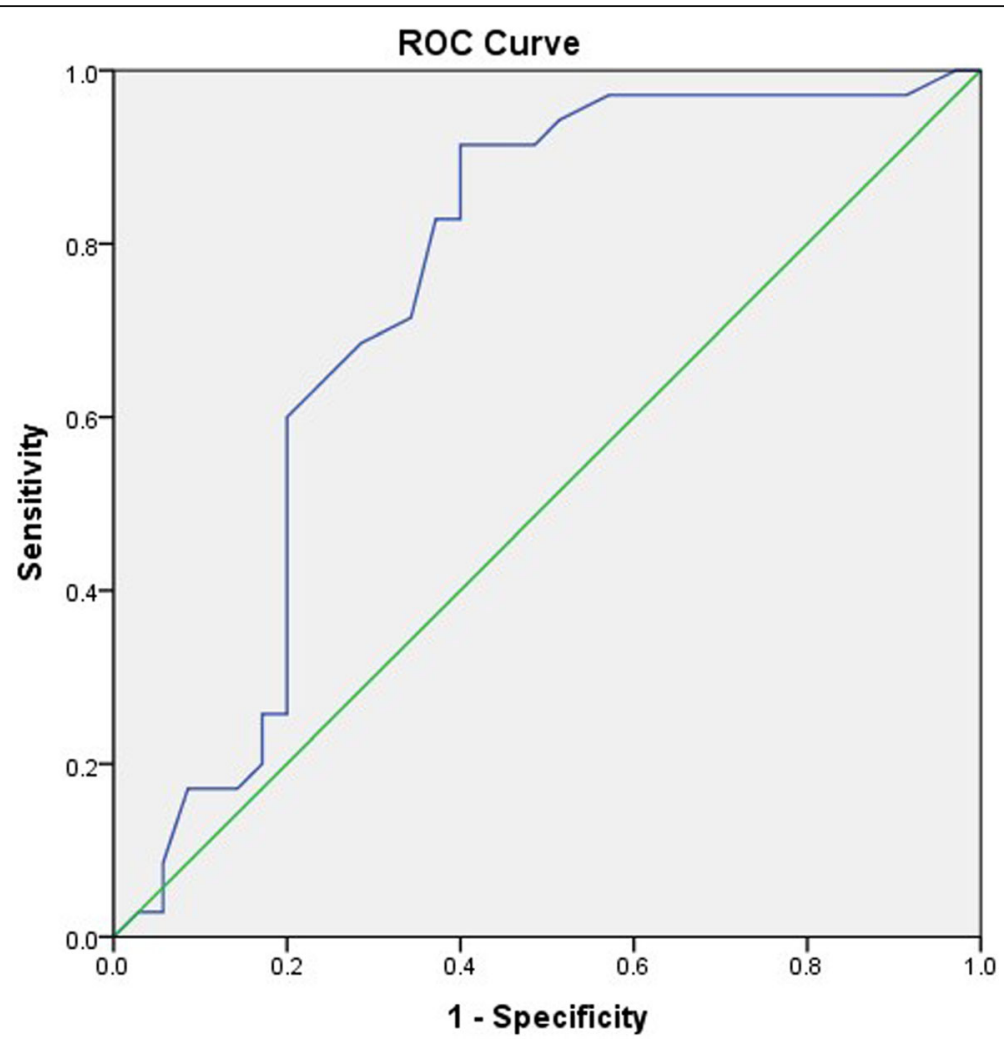

Fig. 2 ROC curve of PTX3 for diagnosis of metabolic syndrome

(FBS), TG, ALT, AST, total and direct bilirubin, while it correlated negatively with platelet count and HDL. Also, patients with metabolic syndrome in the current study showed higher levels of PTX3 than those without metabolic syndrome. A cut-off value for PTX3 $\geq 1.8 \mathrm{ng} / \mathrm{ml}$ was the best in predicting metabolic syndrome with a high sensitivity and a moderate specificity. Similarly, Kardas et al. [22] found significant higher concentrations of plasma PTX3 in obese children and adolescents with metabolic syndrome and higher triglyceride levels, and PTX3 levels correlated negatively with HDL cholesterol in their study. This is contrary to others in the literature who found PTX3 inversely related to obesity and that it increases with weight loss and exercise [23, 24].

Significantly high body mass index and waist circumference were found in NAFLD patients with or without chronic HCV infection in comparison to healthy control subjects. This is like the results of Kowdley et al. [25], Sobhonslidsuk et al. [26], Marchesini et al. [27], and the Rotterdam study of Edith et al. [28]. Steatosis results from enhanced lipogenesis, increased stability of lipid droplets, reduced lipoprotein secretion, and altered mitochondrial function [29]. Hepatic steatosis is present in about $50 \%$ of patients with HCV. Genotype 3 was found to be independently associated with hepatic steatosis. In those with other genotypes of $\mathrm{HCV}$, steatosis was associated with features of the metabolic syndrome. The presence of hepatic steatosis was related to the presence of insulin resistance [30].

Several studies, including the current one, revealed significant higher ALT and AST levels in NAFLD with or without $\mathrm{HCV}$ patients than control subjects. Increased hepatic enzyme levels are indicators of hepatocellular necrosis whether due to NAFLD or chronic HCV [24, 31, 32].

The current study revealed significant higher levels of FBS, post prandial blood sugar, triglycerides, total cholesterol, LDL, and significant lower HDL in NAFLD patients with or without chronic HCV infection than in healthy controls. This agreed with Marchesini et al. [27], the Rotterdam study by Edith et al. [28], Dixon et al. [29], Nakahara et al. [32], and Poynard et al. [33]. NAFLD and type 2 diabetes mellitus (T2DM) frequently coexist because these conditions share common risk factors of excess adiposity, higher lipids, and insulin resistance.

\section{Conclusion}

Serum PTX3 level in patients with concomitant NAFLD and $\mathrm{HCV}$ infection apparently reflects inflammatory response due to changes in metabolic profile, rather than that caused by infection itself, making PTX possibly useful in identifying those in risk of developing metabolic syndrome. Future studies would better use either liver biopsy or MR elastography to diagnose NAFLD. 


\section{Abbreviations}

ALT: Alanine aminotransferase; AST: Aspartate aminotransferase; BMI: Body mass index; CRP: C-reactive protein; FB: Fasting blood sugar; HCC: Hepatocellular carcinoma; HCV: Hepatitis C virus; HDL: High density lipoprotein; IL-1ß: Interleukin-1ß; LDL: Low density lipoprotein; LPS: Lipopolysaccharides; NAFLD: Non-alcoholic fatty liver disease; NASH: Non-alcoholic steatohepatitis; PPBG: Postprandial blood glucose; PTX3: Pentraxin-3; TG: Triglycerides; TNF-a: Tumor necrosis factor alpha

\section{Acknowledgements}

Not applicable.

\section{Authors' contributions}

MM contributed in the conception and the design of the work and in the revision of the manuscript. SS contributed in writing of the manuscript, revision of the work, and publication process. MR contributed in writing of the manuscript and revision of the work. SA contributed in revision of the work and acceptance of the final form of the manuscript. EA contributed in collecting the data and doing the statistical work. All authors have read and approved the manuscript.

\section{Funding}

This research did not receive any specific grant from funding agencies in the public, commercial, or not-for-profit sectors.

\section{Availability of data and materials}

All data and materials are available.

\section{Ethics approval and consent to participate}

This study was reviewed and approved by the Research Ethics Committee of the Faculty of Medicine, Ain Shams University (Ethics committee reference number 136/2015).

\section{Ethics approval}

All procedures performed in studies involving human participants were in accordance with the ethical standards of the institutional and/or national research committee and with the 1964 Helsinki declaration and its later amendments or comparable ethical standards. Informed written consent was obtained from all individual participants included in the study.

\section{Consent for publication}

Not applicable.

\section{Competing interests}

The authors declare that they have no competing interests.

\section{Author details}

${ }^{1}$ Internal Medicine Department, Faculty of Medicine, Ain Shams University, Cairo 11566, Egypt. ${ }^{2}$ Clinical Pathology Department, Faculty of Medicine, Ain Shams University, Cairo 11566, Egypt. ${ }^{3}$ Department of Tropical Medicine, Faculty of Medicine, Ain Shams University, Cairo 11566, Egypt.

Received: 12 July 2019 Accepted: 30 October 2019

Published online: 09 December 2019

\section{References}

1. Matteoni CA, Younossi ZM, Gramiich TE, Boparai N, Liu YC, McCullough AJ (1999) Nonalcoholic fatty liver disease: a spectrum of clinical and pathological severity. Gastroenterology 116:1413-1419

2. Angelico F, Del Ben M, Conti R, Francioso S, Feole K, Maccioni D, Antonini TM, Alessandri C (2003) Nonalcoholic fatty liver syndrome: a hepatic consequence of common metabolic disease. J Gastroenterol Hepatol 18:588-594

3. Yoneda M, Uchiyama T, Kato SE, Endo H, Fujita K, Yoneda K, Inamori M, Nozaki $Y$ et al (2008) Plasma Pentraxin 3 is a novel marker for nonalcoholic steatohepatitis (NASH). BMC Gastroenterol 8:53

4. Norata GD, Garlanda C, Catapano AL (2010) The long pentraxin PTX3: a modulator of the immunoinflammatory response in atherosclerosis and cardiovascular diseases. Trends Cardiovasc Med 20:35-40

5. Mantovani A, Garlanda C. Battazzi B (2003) Pentraxin 3, a nonredundant soluble pattern recognition receptor involved in innate immunity. Vaccine 21:S43-\$47
6. Muller B, Peri G, Doni A, Torri V, Landmann R, Bottazzi B, Mantovani A (2001) Circulating levels of the long pentraxin PTX3 correlate with severity of infection in critically ill patients. Crit Care Med 29:1404-1407

7. Kralj D, Virovic Jukic L, Stojsavljevic S, Duvnjak M, Smolic M, Curcic IB (2016) Hepatitis C virus, insulin resistance, and steatosis. J Clin Translational Hepatol 4:66-75

8. Grundy SM, Cleeman JI, Daniels SR, Donato KA, Eckel RH, Franklin BA, Gordon DJ, Krauss RM et al (2005) Diagnosis and management of the metabolic syndrome: an American Heart Association/National Heart, Lung, and Blood Institute Scientific Statement. Circulation 112:2735-2752

9. Sanyal AJ (2002) Treatment of non-alcoholic fatty liver disease. J Gastroenterol Hepatol 17:S385-S388

10. Erickson SK (2009) Nonalcoholic fatty liver disease. J Lipid Res 50:S412-S416

11. Bottazzi B, Garlanda C, Salvatori G, Jeannin P, Manfredi A, Mantovani A (2006) Pentraxins as a key component of innate immunity. Curr Opin Immunol 18:10-15

12. Ortega-Hernandez OD, Bassi N, Shoenfeld Y, Anaya JM (2009) The long pentraxin 3 and its role in autoimmunity. Semin Arthritis Rheum 54:38-39

13. Mantovani A, Garlanda C, Bottazzi B (2003) Pentraxin 3, a non-redundant soluble pattern recognition receptor involved in innate immunity. Vaccine 21:S43-\$47

14. Strassburg MM, Manns MP (2006) Approaches to liver biopsy techniquesrevisited. Semin Liver Dis 26:318-327

15. Thierry P, Rachel M, Patrick I, Imbert-Bismut F, Thabut D, Messous D et al (2008) Assessment of liver fibrosis: noninvasive means. Saud J Gasterentrol 14:163-173

16. Kadir O, Omer K, Tolga D, Ozen A, Demirci H, Yesildal F, Kantarcioglu M, Turker T et al (2016) Pentraxin 3 is a predictor for fibrosis and arterial stiffness in patients with nonalcoholic fatty liver disease. Gastroenterol Res Pract 2016:(1417962):7. https://doi.org/10.1155/2016/1417962

17. Maleki I, Rastgar A, Hosseini V, Taghvaei T, Rafiei A, Barzin M, Torabizadeh Z Naghshvar F et al (2014) High sensitive CRP and pentraxine 3 as noninvasive biomarkers of nonalcoholic fatty liver disease. Eur Rev Med Pharmacol Sci 18:1583-1590

18. Choi B, Chung EJ (2016) Pentraxine 3 (PTX3) as a biomarker of liver disease. In: Preedy VR (ed) Biomarkers in liver disease: methods, discoveries and applications. Biomedical and Life Sciences, pp 1-20. https://doi.org/10.1007/ 978-94-007-7742-2_32-1

19. Carmo RF, Aroucha D, Vasconcelos LR, Pereira LM, Moura P, Cavalcanti MS (2016) Genetic variation in PTX3 and plasma levels associated with hepatocellular carcinoma in patients with HCV. J Viral Hepat 23(2):116-122

20. Doni A, Peri G, Chieppa M, Allavena P, Pasqualini F, Vago L, Romani L, Garlanda C, Mantovani A (2003) Production of the soluble pattern recognition receptor PTX3 by myeloid, but not plasmacytoid, dendritic cells. Eur J Immunol 33(10):2886-2893

21. Suzuki S, Takeishi Y, Niizeki T, Koyama Y, Kitahara T, Sasaki T, Sagara M, Kubota I (2008) Pentraxin 3, a new marker for vascular inflammation, predicts adverse clinical outcomes in patients with heart failure. Am Heart J 155(1):75-81

22. Kardas F, Akın L, Kurtoglu S, Kendirci M, Kardas Z (2015) Plasma pentraxin 3 as a biomarker of metabolic syndrome. Indian J Pediatr 82(1):35-38

23. Witasp A, Carrero J, Michaëlsson K, Ahlström H, Kullberg J, Adamsson V, Risérus U, Larsson A, Helmersson-Karlqvist J et al (2014) Inflammatory biomarker pentraxin 3 (PTX3) in relation to obesity, body fat depots and weight loss. Obesity 22(5):1373-1379

24. Slusher AL, Huang CJ, Acevedo EO (2017) The potential role of aerobic exercise-induced pentraxin 3 on obesity-related inflammation and metabolic dysregulation. Mediators Inflamm 2017;1092738:9. https:/doi.org/ 10.1155/2017/1092738

25. Kowdley KV, Belt P, Wilson LA, Yeh MM, Neuschwander-Tetri BA, Chalasani N, Sanyal AJ, Nelson JE (2012) Serum ferritin is an independent predictor of histology severity and advanced fibrosis in patients with nonalcoholic fatty liver disease. Hepatology 55:77-85

26. Sobhonslidsuk A, Pulsombat A, Kaewdoung P, Petraksa S (2015) Nonalcoholic fatty liver disease (NAFLD) and significant hepatic fibrosis defined by non-invasive assessment in patients with type 2 diabetes. Asian Pac J Cancer Prev 16(5):1789-1794

27. Marchesini G, Brizi M, Bianchi G, Tomassetti S, Bugianesi E, Lenzi M (2001) Nonalcoholic fatty liver disease: a feature of the metabolic syndrome. Diabetes 50(8):1844-1850

28. Koehler EM, Schouten JNL, van Rooij FJ, Hofman A, Stricker BH, Janssen HL (2012) Prevalence of and risk factors for non-alcoholic fatty liver disease in the elderly: results from the Rotterdam Study. J Hepatol 57:1305-1311 
29. Dixon JB, Bhathal PS, O'Brien PE (2001) Nonalcoholic fatty liver disease: predictors of nonalcoholic steatohepatitis and liver fibrosis in the severely obese. Gastroenterology 121(1):91-100

30. Lonardo A, Adinolfi LE, Loria P, Carulli N, Ruggiero G, Day CP (2004)

Steatosis and hepatitis $C$ virus: mechanisms and significance for hepatic and extrahepatic disease. Gastroenterology 126:586-597

31. Fracanzani AL, Valenti L, Bugianesi $\mathrm{E}$, Andreoletti M, Colli A, Vanni E, Bertell C, Fatta E et al (2008) Risk of severe liver disease in nonalcoholic fatty liver disease with normal aminotransferase levels: a role for insulin resistance and diabetes. Hepatology 48:792-798

32. Nakahara $T$, Hyoqo $H$, Yoneda M, Sumida $Y$, Equchi $Y$, Fujii $H$, Ono M, Kawaguchi T et al (2014) Type 2 diabetes mellitus is associated with the fibrosis severity in patients with nonalcoholic fatty liver disease in a large retrospective cohort of Japanese patients. J Gastroenterol 49(11):1477-1484

33. Poynard T, Ratziu V, Charlotte F, Messous D, Munteanu M, Imbert-Bismut F, Massard J, Bonyhay L et al (2006) Diagnostic value of biochemical markers (NASH) for prediction NASH in patients with NAFLD. BMC Gastroenterol 6:34

\section{Publisher's Note}

Springer Nature remains neutral with regard to jurisdictional claims in published maps and institutional affiliations.

\section{Submit your manuscript to a SpringerOpen ${ }^{\circ}$ journal and benefit from:}

- Convenient online submission

- Rigorous peer review

- Open access: articles freely available online

- High visibility within the field

- Retaining the copyright to your article

Submit your next manuscript at $\boldsymbol{\nabla}$ springeropen.com 